\title{
REFLEXIONES SOBRE LAS CANTIGAS DE SANTA MARÍA Y SU RELACIÓN CON OTROS MARIALES ROMANCES
}

\author{
Elvira Fidalgo Francisco \\ Universidade de Santiago de Compostela \\ elvira.fidalgo@usc.es
}

Cuando pensamos en la figura de Alfonso X, pensamos en un monarca crucial en la historia del reino de Castilla, que tuvo que enfrentarse a serios problemas políticos y económicos, en su incesante labor reconquistadora, en sus problemas sucesorios pero, al mismo tiempo, surge con igual fuerza la imagen del rey sabio, interesado por la labor que, bajo su mandato, estaba desarrollando un, seguramente muy elevado número de estudiosos, grandes conocedores de los diversos campos del saber que conformaban su famoso scriptorium.

La extraordinaria producción científica emanada de este entorno se justifica por el acceso a numerosos textos clásicos de tradición grecolatina, algunos de ellos accesibles gracias a las traducciones árabes hechas en su propia corte, y a la participación de científicos judíos, que, en consonancia con los anteriores, abrieron las puertas del conocimiento a nuevas corrientes filosóficas, científicas, literarias y estéticas específicas de otras culturas. En otra escala y proporción, la explicación podría ser igualmente aplicable al ámbito historiográfico y al legislativo e, incluso, en el nivel correspondiente, a su producción poética. La participación personal del rey y, sobre todo, el impulso que proporciona a una corriente trovadoresca que, justamente, se hace más vigorosa coincidiendo con su reinado, ha sido objeto de diferentes estudios que demuestran la sólida imbricación de asuntos políticos y poéticos durante su reinado (Alvar 1977; Beltrán 2005; Resende 1995: 62-86; Alvar 2020).

Lo dicho hasta ahora con carácter general para explicar su variada producción literaria es perfectamente aplicable a las Cantigas de Santa María 
(CSM): nacen en el seno de la escuela poética que él impulsa (Fidalgo 20122013), y en su elaboración han participado numerosos especialistas ${ }^{1}$, entre los cuales estarían los encargados de hacer acopio de fuentes que pudiesen servir de modelo o inspiración para los nuevos productos; esa riqueza de fuentes se vería igualmente reflejada en los contenidos y en las formas, ya que, siguiendo la práctica habitual de los talleres alfonsíes, se tradujeron, adaptaron y compusieron los modelos según sus intereses y necesidades ${ }^{2}$.

Quiénes participaron en este acopio de fuentes es tierra tan ignota como la identidad de los autores que participaron en la propia composición de las cantigas. De entre los primeros, conocemos el nombre de un colaborador seguro, el benedictino Bernardo de Brihuega, canónigo de la catedral de Sevilla, pues él mismo revela estar trabajando a las órdenes del rey, quien insiste en que no dejen de rastrearse las bibliotecas de los monasterios de su reino en busca de posible nuevo material de construcción:

E porende nom se deve maravilhar nunhũu se eu, Bernaldo de Briuega, clerigo do muy nobre meu senhor el Rey dom Afonso, avendo mandamento delle de traladar as vidas dos martires e dos outros santos, faço ende muytos livros. E mayormente avendos de achegar per seu mãdado, per muytos logares departidos, e nom os achando as sazoões çertas que os mester avia [...] Mas elle, veendo que minguavã hy muytos dos que ele sabia e avia hy algũas que nõ eram bem compridas, mandou ir buscar e ẽmendar, per todolos moesteyros de seus reynos... ${ }^{3}$

El otro nombre que con frecuencia viene aparejado a este es el de Gil de Zamora, franciscano, posible confesor del rey, tutor de su hijo Sancho y autor de numerosas obras en latín ${ }^{4}$, entre ellas un Liber Mariae (Fita 1885), que

\footnotetext{
${ }^{1}$ Baste pensar en la «tridimensionalidad» de esta obra excelsa, cuyas composiciones poéticas van acompañadas de una tonada melódica que convierten el conjunto en el mejor y mayor repertorio musical de la Edad Media y que dos de los códices que transmiten la colección presentarían un relato iconográfico paralelo al textual si uno de ellos, el Ms. BR 20 de la biblioteca florentina no hubiese quedado incompleto.

${ }^{2} \mathrm{~A}$ las fuentes que estarían a disposición del scriptorium real ya se ha dedicado un capítulo específico en este volumen y a él remito para una visión detallada. Para la descripción de las fases presumiblemente seguidas en la confección de la obra, véase Parkinson 2006 y 2011. El propio rey alude en sus versos al proceso de producción de la obra: «E daquest'un miragre mui fremoso direi / que fez Santa Maria, per com'escrit'achei / en un livr', e d'ontr'outros traladar-o mandei / e un cantar eu fige / segund'esta razón» (CSM 284, vv. 5-8). Transcribo los textos por la edición de Mettmann (1996-1989) y sigo su numeración.

${ }^{3}$ La cita es de M. Martins (1963: 421). En efecto, el de Brihuega recoge en cinco libros las vidas y pasiones de los apóstoles, mártires, confesores, vírgenes y otros santos. Las últimas noticias señalan que el briocano podría estar haciendo acopio de material tanto para una magna obra hagiográfica por indicación del Sabio como documentación para continuar la redacción de la General Estoria (Bautista 2015; Pichel: 2021)

${ }^{4}$ Juan Gil escribe un buen número de obras de estilos diferentes. De las que pudiesen tener cierta influencia en la formación del cancionero alfonsí (sin que con ello esté indicando una relación directa), 
recoge cincuenta milagros, de los cuales, treinta están también en las CSM, aunque solo una pudo haber sido la fuente directa de la adaptación alfonsís ${ }^{5}$.

Es casi seguro que más ayuntadores de livros habrían colaborado con el mismo propósito de reunir la mayor cantidad posible de manuscritos que contuviesen leyendas marianas sobre las que inspirarse ${ }^{6}$, pues una vertiginosa corriente de piedad mariana circulaba por Occidente plasmando en latín sus más conmovedores milagros. No obstante, sobre todo después del cuarto concilio lateranense de 1215, el romance asoma a esta tradición ${ }^{7}$ (como ya lo había hecho a otras anteriormente), atendiendo al consejo emanado de ejercer la predicación en la lengua que mejor entendiesen los feligreses y acercar, así, la palabra de Dios al pueblo indocto. Esta recomendación vale igualmente para las obras hagiográficas, de tan alto valor propedéutico, pero que (antes del último cuarto del siglo XII) venían mayoritariamente transmitidas en latín, de difícil comprensión incluso para una gran mayoría de clérigos de muy escasa formación académica. En este contexto general podríamos encuadrar la figura de Gonzalo de Berceo, monje culto, formado probablemente en la recién fundada universidad palentina y autor de una colección de veinticinco milagros de la Virgen conocida como los Milagros de Nuestra Señora ${ }^{8}$. Compuestos aproximadamente entre 1246-1252, perfectos representantes del «mester de clerecía», estos relatos de milagros oficiados por la Virgen podrían haberse utilizado como exempla con los que el maestro Gonzalo ilustraría los versos más oscuros de la simbólica Introducción que los precede, cargada de doctrina mariana (Uría 1997: XXII). Pudiéramos creer que, en alguna de las

cabe destacar un Ars música y el Dictaminis epithalamium, que es un tratado de retórica en el que se dan instrucciones para escribir misivas, panegíricos, textos laudatorios, etc.

${ }^{5}$ Se trata de la CSM 34, que, en opinión de Mettmann (1991: 82) está más próxima a la versión del colaborador que a otras fuentes propuestas. Gil de Zamora era, además, un experto músico, por lo que no podemos descartar su participación en este componente de las Cantigas.

${ }^{6}$ Uno de ellos podría ser el dominico Rodrigo Cerrato, colector y redactor de vidas de santos; vid. Dondaine 1974.

${ }^{7}$ Aunque tenemos constancia de la existencia de colecciones romances más antiguas, como el Gracial de Adgar, copiado en anglonormando, al sur de la actual Inglaterra y datado aproximadamente en 1170 (Kuntsmann 1982).

${ }^{8}$ Vid. Baños (1997), que ofrece la última edición crítica del texto de los Milagros; a ella me refiero en adelante. Berceo adapta al castellano una fuente latina, no identificable al cien por cien, pero que podría ser una colección hermana a la que se guarda en el $M S 110$ de la Biblioteca Nacional de España (y que Baños incluye al final de su edición), que contiene todos los milagros de la colección de Berceo (y alguno más) y en el mismo orden, excepto el último y la Introducción, de autoría personal del riojano (Baños 1997: XLII-XLVI). El editor resalta también el Códice Alc. 39 de la Biblioteca nacional de Lisboa, procedente del monasterio da Alcobaça (Nascimento 2004), que guarda gran similitud con el anterior en su contenido (pero no en la ordenación). En cualquier caso, ambos códices latinos coinciden en transmitir el conocidísimo libro de Hugo Farsitus, Libellus de Miraculis Beatae Mariae in urbe Suessioniensi (PL 179, 1774-1800), compilado en 1143 en el santuario de Soissons, importante centro de peregrinación y de producción libraria en la Edad Media. 
incursiones a este y otro monasterio, obedeciendo las órdenes del rey, alguno de los colaboradores del Sabio llegase a conocer esta colección en castellano y que de ahí surgiese la idea y parte de la materia prima, aunque parece poco probable que así haya sido 9 . Aunque durante algún tiempo se sostuvo que Berceo habría compuesto estos milagros para atraer a peregrinos a San Millán y que, tal vez, este factor pudiese influir en la fama de tales relatos, últimamente la crítica se decanta por la finalidad propedéutica que hemos apuntado, de modo que los Milagros no habrían tenido mayor repercusión fuera del monasterio donde habían sido $\operatorname{creados}^{10}$, aunque esto no es óbice para que uno de los colaboradores del rey los conociese y se llevase (prestado) un ejemplar para usarlo en la corte ${ }^{11}$. Sin embargo, y aun considerando la posibilidad de que Alfonso hubiese conocido la colección del riojano, a juzgar por el resultado de su propio marial, no debió de interesarle más de lo que le interesaron los repertorios latinos que consiguió tener a su alcance.

La colección que, por diversas razones, sí debió de llamar su atención fue la compilada por Gautier de Coinci entre 1218 y $1232^{12}$ y, en mi opinión, es probable que la haya conocido físicamente. Ya en su momento Teresa Marullo (1934: 497) supuso que «il re sapiente ha attinto il maggior numero di leggende all'opera di Gautier di Coincy» y señaló este repertorio francés como la fuente de inspiración más segura para el marial alfonsí. De los 58 Miracles, 48 están recogidos en las CSM y 25 de ellos resultarían, no de las coincidencias de la consulta de una misma fuente, sino de una auténtica adaptación en el scriptorium regio de los milagros del francés, por lo menos,

\footnotetext{
${ }^{9}$ Menos probable todavía me parece que Alfonso X, en su visita al monasterio de Silos en 1255 , como testifica Pedro Marín en el tercer y cuarto relatos, se hubiese inspirado en alguno de los intentos de compilación de los milagros de santo Domingo que acabarán reunidos en los Miraculos romançados de Pedro Marín, redactada finalmente en torno a 1284 (Anton 1988), pero que recoge milagros oficiados por intervención del santo desde 1232. Esta visita está constatada históricamente (Salvador 2003: 122).

${ }^{10}$ Los manuscritos medievales conservados proceden o bien del monasterio de San Millán o del monasterio de Silos y sus casas filiales, como San Martín de Madrid. El Marqués de Santillana en su Carta Proemio... no cita las obras de Berceo entre las que propone como modelos ejemplares del mester de clerecía (Baños 1997: Xxxi, n. 3), por lo que es difícil pensar que esta colección gozase de amplia circulación fuera del ámbito monástico señalado.

${ }^{11}$ De esta práctica tenemos constancia por la conservación de dos cartas enviadas por el rey y fechadas en 1270 en las que se reconoce que se le han prestado «19 libros de letra antigua» procedentes de distintos monasterios, aunque se refiere, en esta ocasión, a tratados de retórica y gramática (Faulhaber 1972: 44), pero la práctica podría ser extensible al terreno de la historiografía y a otras materias. Los libros pedidos prestados a los monasterios de Nájera y Albelda eran muchos y de temas muy variados.

${ }^{12}$ Los Miracles de Nostre Dame (en adelante MND o Miracles) están formados por dos libros simétricos en su factura: un prólogo, unas composiciones de tono lírico en honor de la Virgen, los milagros y una nueva serie de composiciones laudatorias para cerrar el libro. Utilizo la edición de Koenig (1955, $1961,1966,1970$ ) en cuatro volúmenes y a ella remito tanto para la transcripción de los textos como para la identificación de los mismos.
} 
en lo que respecta a la primera colección de cien cantigas. Del número de Miracles coincidentes con las CSM, veintiocho se sitúan antes de la CSM 50 y veinte entre esta y la CSM 100; una más está ya en el apéndice y otra no vuelve a repetirse en los otros códices posteriores, así que, en efecto, me parece difícil negar cierta relación entre ambos colectores de milagros de la Virgen $^{13}$. Por otro lado, la misma Marullo excluía dos milagros del francés como fuente directa para las CSM 37 y 61 (que, conteniendo el mismo relato, discrepan demasiado en los detalles) y exponía sus dudas con respecto a bastantes otros. Así, en 1991, Walter Mettmann recogió el guante y analizó esas veintidós cantigas, confrontándolas con los Miracles y confirmó la filiación directa para un total de treinta y seis. Añadía, además, que, teniendo en cuenta que «seguramente não era grande o número de pessoas do séquito real que possuía bons conhecimentos de lingua francesa», el mismo traductor pudo haber sido el compositor de esas cantigas (p. 84).

Ahora bien, ¿pudo haber tenido la colección francesa ante sus ojos?, ¿cómo pudo haber llegado a sus manos? Particularmente, me parece factible que, teniendo en cuenta la fama del marial francés y los intereses del Sabio, llegase a conocerlo. Creo que podrían existir dos probables vías de entrada, aunque me resultan imposibles de corroborar. Una es la noticia, no confirmada, de que un ejemplar de los $M N D$ figurase entre los regalos enviados al rey por su primo, el rey Luis IX de Francia, según la información aportada por el Marqués de Valmar, aunque, en realidad, el marqués dice que el regalo hecho por san Luis era un volumen que contenía el Speculum historiale del dominico Vicente de Beauvais (Valmar 1990: III). Sin embargo, teniendo en cuenta la notoriedad y repercusión que los $M N D$ habían tenido en tierras galas, no sería extraño que también se hubiese podido agregar este libro a los presentes enviados. Recuérdese que el rey francés, en torno a 1248, había enviado una impresionante colección de reliquias de santos, de Cristo y de la misma Virgen, con que se vería incrementado el conjunto relicario de la catedral toledana (Miquel 2017: 746). Los obsequios contribuirían a fortalecer la relación entre los dos reinos gobernados por reyes con estrechos vínculos

\footnotetext{
${ }^{13}$ Parkinson (2011: 90), sin embrago, rechaza una dependencia tan directa de la obra del francés y explica las coincidencias porque tanto uno como otro han podido beber de las mismas fuentes (como el Mariale Magnum de Vincent de Beauvais o el marial de Hugo Farsitus, por ejemplo) que circulaban corrientemente por Occidente. Le resulta extraño que no se mencione ningún ejemplar de los $M N D$ en el testamento del rey y añade que «no early Gautier manuscripts survive in Spain» y que la serie de coincidencias señaladas por Marullo «rests generally on textual coincidences rather than on uniquely shared narrative developments». Pero, al mismo tiempo, en la p. 92, señala que «It is more likely that at some point (or several points) in the composition cycle, Gautier was systematically consulted», o sea, que en el scriptorium en algún momento se debió de tener acceso a un ejemplar de los Miracles.
} 
familiares que todavía habrían de estrecharlos más gracias al enlace matrimonial de los vástagos de ambas familias ${ }^{14}$, que se vieron consolidados en 1269 cuando Fernando contrajo matrimonio con Blanca, hija de san Luis. Ambos momentos -particularmente el segundo- pudieron haber supuesto ocasiones propicias para el intercambio de presentes protocolarios, que podrían haber incluido libros de especial interés para el Sabio, como la Biblia Moralizada en tres tomos, ricamente iluminada, que había sido mandada confeccionar por la reina Blanca de Castilla para su hijo, el que sería rey de Francia, y que Alfonso menciona en su testamento como regalo del rey francés.

La otra posible vía de entrada pudo ser el equipaje de Fray Gil de Zamora que, en 1272 o 73 fue enviado a París, a estudiar en la universidad donde ejercía su magisterio el ilustre filósofo san Buenaventura, superior general de los franciscanos. A su regreso a Castilla ${ }^{15}$, además de una elevada formación, traería el caudal de la ferviente espiritualidad franciscana que habría bebido de las enseñanzas de su maestro y hasta es posible que se trajese algunos libros (o, al menos, noticias sobre ellos) que juzgase de interés para el monarca. Este podría ser el caso de los Miracles de Notre Dame, cuya belleza $\mathrm{y}$ «modernidad» pudo haber inducido al rey a replantearse (y a la vez, a reafirmarse en) el proyecto que había emprendido ${ }^{16}$. Hacia el último cuarto del siglo XIII, la fama de Gautier habría llegado a cualquier rincón de Francia, puesto que ya en vida había sido un compositor célebre gracias a su mariologio y sus milagros fueron imitados en todas partes por cualquiera que cultivase la hagiografía. Siendo así, no parece fuera de lugar que en la universidad

${ }^{14}$ El 20 de agosto de 1255, Luis, segundo hijo del Santo, fue prometido a la infanta Berenguela de Castilla, hija mayor de Alfonso, que, en aquel momento, era la heredera de Castilla. Sin embargo, poco después de los esponsales, nació Fernando de la Cerda, desplazando a su hermana en la línea de sucesión.

${ }^{15}$ Es de suponer que en más de cuatro años tal vez hubiese regresado alguna vez antes del abandono definitivo de las tierras galas o que hubiese mantenido correspondencia con la corte.

${ }^{16}$ Por esas fechas, Alfonso X ya estaba profundamente interesado por las composiciones en honor de la Virgen. Hacia 1269, su fama como «cantor de la Virgen» debía de ser notable, a juzgar por la composición Canço de Madona Santa Maria que le dedica Cerverí de Girona cuando llegó a Toledo entre el séquito del infante don Pedro de Aragón (Alvar 1977, Cabré 2017), pero la primera colección de cien cantigas seguramente no fue empezada a copiar como tal hasta 1270 y en 1276 estaba ya acabada, a juzgar por la noticia que se ofrece en la CSM 209, v. 29: «mas mandei o Livro dela aduzer». Hacia 1280 se empezaría a confeccionar el primer «códice rico» y hacia 1282 se acometería la copia del segundo «códice rico» (F) y el de E, así que pudiera ser que el manuscrito de los $M N D$ que conociese Gil de Zamora contuviese las ilustraciones que Alfonso todavía no había ni imaginado, a juzgar por la sencillez del Códice To. Los manuscritos de los $M N D$ más antiguos conservados (por ejemplo B, H, L, T o el icónico Manuscrito R de la Biblioteca de San Petersburgo, datado en 1266, contienen entre 64 y 77 ilustraciones y el de Besançon (T) 186 (Stones 2006: 368-371), así que de alguno de ellos pudo haber tomado la idea que transmitió al rey, si no trajo una copia física. La evolución del proyecto alfonsí en su contexto está muy bien descrita en Fernández Fernández 2011 y en los ya citados Parkinson 2006 y 2011. En esa misma edición, véase el estudio general de la iconografía del Códice Rico (Chico Picaza 2011). 
parisina, quien aspirase a incrementar su formación teológica, conociese de primera mano la obra del prior de Vic-sur-Aisne y, en el caso de Fray Gil, estando al tanto del interés del monarca castellano por las colecciones de milagros marianos, hubiese traído uno de los innumerables manuscritos en los que se había copiado la obra del francés ${ }^{17}$.

Si esta línea argumental fuese aceptable, ¿por qué pudo haber prestado más atención a este proyecto que al de Berceo? No habrá sido el contenido de los milagros, que, en parte, común a ambos repertorios estaría al alcance del rey en las mismas versiones latinas en la que habrían bebido los romances. Tampoco creo que haya que encontrar la explicación en cómo se han transmitido esos milagros, puesto que, en mi opinión, los textos de Berceo habrían resultado más fáciles de adaptar a los versos gallegos que los densos milagros en francés, salpicados de constantes digresiones que distraen de la línea argumental y que se ven lastrados por una larga cola final de tono sermonario. A mi modo de ver, lo que sorprendió al monarca castellano, siempre en busca de cualquier novedad en cualquier campo del saber, fue el «libro»en sí mismo: una amplia y ordenada selección de milagros de la Virgen, identificados de manera individual por una rúbrica $\mathrm{y}$, en su conjunto, encajados entre una serie de canciones (con su notación musical) de alabanza a la Virgen al inicio del Primer Libro y al final del Libro Segundo ${ }^{18}$, que funcionaban como

\footnotetext{
${ }^{17}$ Gracias al clásico trabajo de A. Ducrot-Grandereye (1980), sabemos que se conservan ciento catorce manuscritos que contienen el marial francés, número muy superior al de cualquier otra obra contemporánea de materia similar. De ellos, veinte transmiten la obra completa, con sus milagros y canciones, veintisiete contienen la obra casi completa y setenta y seis transmiten alguno de los milagros o canciones (Stones 2010: 238-239). De los manuscritos conservados que transmiten la colección completa, uno está fechado en 1266 y hay otro de 1267 o 68, aunque este no contiene la colección íntegra. De antes del siglo XIV persisten un total de cincuenta y nueve manuscritos que transmiten la obra o algún milagro o canción (Duys 2006: 353-355), así que es fácil deducir la enorme fama que adquirieron los milagros del francés y el elevado número de libros que los contenían hacia el último cuarto del siglo XIII.

${ }^{18} \mathrm{El}$ mariologio del prior de Vic-sur-Aisne, tal como aparece en los manuscritos que recogen la obra completa, consta de dos libros (Libro I y Libro II). El primero está formado por dos prólogos (I Pr 1: Ci commence li prologues seur les myracles Nostre Dame que Gautieurs, prieus de Vi, moines de Saint Mart, translata y I Pr 2: Ainz qu'ouvrir welle le grant libre), y siete canciones (prières) a la Virgen, seguidas de treinta y tres milagros y la leyenda de Santa Leocadia, composición original de Gautier con la que se cierra este volumen. El segundo libro se abre con un nuevo prólogo (II Pr. 1: Ci commence li prologues en la seconde partie) al que sigue un grupo de siete nuevas canciones, veinticuatro milagros y un Epílogo (Qui ces myracles a leüs), una composición de carácter moral (II Dout 34: Gautiers, qui est de cors e d'ame) de 2.630 versos con el que cierra el libro (A cest vers ci mon libre fin, v. 2.629). Seguidamente empiezan los Cinco Salus de Notre Dame, precedidos de su Prólogo y seguidos por una canción y tres oraciones a la Virgen y una última oración en la que Gautier solicita la protección de Dios para su alma. Esta es la disposición que sigue Koening (1966-1970) en su edición que basa, esencialmente, en el Ms. L (Paris, BNF, fr. 22928). Ducrot-Granderye (1932: 159-169) describe la colectánea de los MND como el resultado de un proyecto que se ha llevado a cabo en tres fases consecutivas en las que se han ido añadiendo materiales al programa inicial que va perfeccionando su estructura. La forma inicial de la obra (reflejada en trece copias del total de manuscritos conservados) contendría I Pr 1, I Mir 10; I Mir 11 (en
} 
prólogo y epílogo de una obra cerrada. La presencia, ya en los ejemplares más antiguos de los conservados, de capitales historiadas que mostraban imágenes relativas al milagro que presidían e, incluso, con la representación de dos o tres episodios del relato en una ilustración al comienzo de determinadas composiciones -algunas ya en formato rectangular, dividido en cuatro viñetas con imágenes- [fig. 1], y folios completos iluminados ${ }^{19}$, sería otro elemento que jugase a favor de esta colección como su preferida ${ }^{20}$.

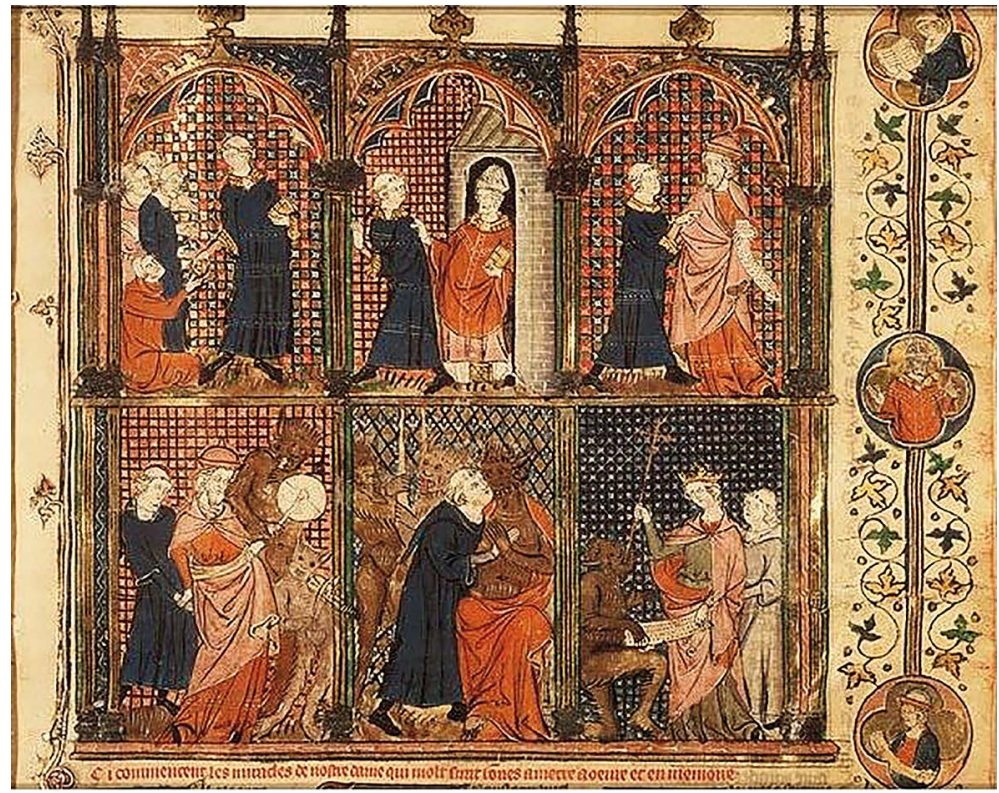

una versión reducida), I Mir 12-43 y II Dout 34 de solo 810 vv. Esta versión confeccionada en torno a 1218 se vería completada en 1222 con las canciones finales del Libro I y su prólogo, los milagros 44-47 del Libro I y una canción del Libro II. Entre 1223 y 1227 se acometería el resto de las composiciones que conforman el total de la colección.

${ }^{19}$ La imagen pertenece al Ms. 71 A 24 de la Koninklijke Bibliotheek (La Haya) y es de 1327, pero podría estar reproduciendo el tipo de ilustración en viñetas que he mencionado. (Imagen de dominio público). Para mayor información acerca de la posible influencia de alguno de los manuscritos de los $M N D$ en el programa iconográfico de las CSM, vid. Sánchez Ameijeiras (2002: 256-268).

${ }^{20}$ Soy consciente de la falta de pruebas para esta suposición e, incluso, de la solidez de los escollos contra los que estas hipótesis tropiezan: las fechas pueden no encajar a menos que se las obligue de alguna manera. Si To se empezó a idear a partir de 1270 con el material fruto de las «adaptaciones» de los $M N D$, Fray Gil llegaría tarde con su información, a menos que un ejemplar de los MND llegase antes al scriptorium, fruto, por ejemplo, de un regalo diplomático (¿1248?, ¿1255?, ¿1269?), como la Biblia Moralizada o el Speculum de Vicente de Beauvais y que el franciscano, a su vuelta, trajese la noticia de nuevos volúmenes, ricamente iluminados, como el de San Petersburgo (Ms R), que se habían confeccionado en fechas más cercanas a su estancia en París (lo cual podría haber dado el impulso necesario para la reorganización, también desde el punto de vista material, de la colección ya iniciada). Otra opción podría ser que alguno 
Sea como fuere, y en la convicción personal de que, en efecto, la colección francesa está detrás del marial alfonsí, creo que existen otras razones que pudieron haber pesado en el plato de la balanza tanto o más que la materia misma de los relatos en un número más elevado que cualquier otro colector y son: 1) la factura interna del contenedor y la distribución de su contenido y 2) la doble lectura que se filtra por las rendijas del relato de espectaculares milagros de la Virgen en favor de sus devotos.

En cuanto al primer aspecto, ambas colecciones coinciden al adoptar el marco lírico que encuadra los textos narrativos y esta disposición excluye la compilación del riojano. Tanto en francés como en gallego nos encontramos una primera composición ${ }^{21}$ de indicación de autoría y presentación de intenciones con la alabanza a la Virgen en el caso de Gautier y algo semejante en las $C S M$, si bien, en este caso, el contenido del largo poema francés se reparte en dos textos, como se recordará, porque quien se presenta como autor es nada menos que un rey. El Prólogo alfonsí, como es de sobra conocido, es una ágil cantiga estructurada sobre la canso trovadoresca provenzal en la que el Sabio, encomendándose a Dios, «ond' o saber ven» (v. 12), se declara trovador de la Virgen y anuncia el abandono de la práctica de la composición de la poesía profana (vv. 24-26) para consagrarse enteramente a mostrar los milagros de la Virgen y cantar sus alabanzas (vv. 15-23), aunque, apelando al tópico exordial de la humilitas (v. 9), duda de sus capacidades para ello. Seguidamente, comienza la edificación del marial con la primera cantiga, de loor, elaborada en torno a los «siete gozos de la Virgen». El «Prologues» de Gautier, por el contrario, es una larga composición de 330 versos dedicados, esencialmente, a cantar «la loenge et la gloire» de Notre Dame, tal como se anunciaba ya en el primer verso. El autor, que no se presenta hasta el final, desvela que va a traducir del latín los milagros para aprovechamiento de quienes no dominan bien la lengua de los clásicos, en una larga secuencia en la que, fiel a su propio estilo, reiterará esta idea varias veces (vv. 6-39),

de sus maestros de retórica, como Ponce de Provenza o Geoffrey de Everseley, que estuvieron en la corte en el tercer cuarto del siglo XIII, provenientes o relacionados con importantes ciudades francesas, hubiesen traído consigo una copia de los $M N D$, teniendo en cuenta los gustos de su dilecto patrono. Pero, en efecto, es raro que no se conserve ni haya referencias a este libro en ningún sitio, sobre todo, si tenía notación musical y miniaturas; no obstante, que no tengamos noticia de la existencia de ningún ejemplar de los $M N D$ en la Península Ibérica, tal como señala Stones (2006) no quiere decir que no hubiese estado, y que se haya perdido su rastro. Hace solo unos pocos años que se ha explicado cómo el Códice F de las CSM ha ido a parar a la biblioteca florentina después de haber pasado por distintas manos (Fernández Fernández 2005), y Stones tampoco aclara cómo ha llegado el Ms. R a la biblioteca de San Petersburgo, por ejemplo. La falta de noticias sobre la existencia del manuscrito no equivale a la no existencia del mismo.

${ }^{21}$ Voy a fijarme, por ahora, en el Códice To, el primero que se ha confeccionado en el scriptorium Alfonsí. El Prólogo es la primera composición (fol. 7v) que nos encontramos después de la Intitulatio en la que se atribuye al rey Alfonso la autoría de la obra (fol. 1r) y del Índice, que ocupa los fols. 1r-7r. 
y solicita, acudiendo igualmente al topos de la humilitas, la sabiduría para hacerlo bien. El resto, como decía, es una extensa alabanza de las virtudes de la Virgen, donde se menciona su virginidad, su maternidad divina, su figura como nueva Eva y su condición de inmejorable abogada nuestra ${ }^{22}$. Cuando, en el verso final, anuncia que va a dar comienzo ya a lo prometido, en realidad, lo que comienza es un segundo prólogo («Ainz qu'ovrir welle le grant libre [...] Canter vos veil deus chançonettes», I Pr 2, vv. 1 y 7) y declara su intención de incorporar, a lo largo de la obra, alguna canción más de su propia autoría (recordemos que confesaba estar traduciendo los milagros que ya estaban escritos), tal como indican los vv. 18-20:

En cest libre volrai planter

De lius en lius chançons noveles

De Nostre Dame mout tres beles

Y, en efecto, antes del primer milagro (el de Teófilo), introduce siete canciones de texto alambicado, sostenido sobre un enrevesado juego de rimas derivadas y mots equivocs que son también marca de su particular estilo, todo ello con la única finalidad de ensalzar a la «Roïne celestre», la «Fontaine de grace», la «Rose fresche et clere» (I Ch 5, v. 1, 37 y 74).

Me pregunto si no habrá sido la reinterpretación de los versos anteriores los que habrían animado a Alfonso a incluir entre las narraciones de milagros sus propias «chançons noveles», pero colocándolas ordenadamente en correspondencia con la adaptación reordenada de toda la obra. Tal vez, de esta propuesta surgiese la cadencia decenal de las cantigas de loor, que destacan por su originalidad (pues tampoco son adaptaciones de textos preexistentes), por su contenido (centrado en la exaltación de las cualidades de la Virgen) y por su forma (puesto que la variedad métrica que exhiben estas composiciones las acerca más a modalidades propias de las cantigas profanas que a las de milagre, en las que se observa un casi total predominio del zéjel), en consonancia con las «chançonettes» (v. 9) del Prior que sobresalen en el conjunto de sus miracles por idénticas razones ${ }^{23}$.

\footnotetext{
${ }^{22}$ Creo que merece la pena señalar los vv. 271-299 en los que, después de haber reiterado que el amor a la Virgen siempre es recompensado, se desarrolla el extenso símil en el que María es comparada a la reina en el ajedrez y su poder sobre las demás piezas del juego en cualquier posición para resaltar la superioridad de la Virgen sobre el diablo. El recurso a potentes imágenes visuales es una marca identificadora del estilo de Gautier que aligera la pesadez de extensas secuencias de versos reiterativos.

${ }^{23}$ Permítaseme apuntar, de paso, que algunas de las melodías presentes en las chansons de los MND fueron aprovechadas como soporte de algunas cantigas, como demostraron Rossi y Disalvo (2009).
} 
Si nos fijamos ahora en el último tramo de la colección de milagros, creo que es obvio que entre el apéndice de las Festas de Santa María y los Salus Nostre Dame podría haber asimismo cierta relación. Tanto Gautier como Alfonso han confeccionado una larga colección de milagros operados por la Virgen en favor de sus devotos, a quienes asiste en diferentes ocasiones y por diferentes causas, y ponen el broche final a esta serie de relatos dirigiendo la mirada exclusivamente hacia la Virgen, enalteciendo de sus virtudes y excelsas cualidades ${ }^{24}$ y requiriendo su protección divina. El colofón del francés consta de un prólogo (II Sal 35) en el que se contraponen las figuras de Eva y la Virgen a través del conocido juego de palíndromos (Ave/Eva) y se da paso a los salus, que son composiciones que se han construido sobre las palabras emitidas por el ángel en la Anunciación. Así, el primero se abre con el «Ave» y se combina con la exaltación del nombre de MARÍA, adecuado únicamente para la figura femenina que lo porta: Ave dame as cinc lettres qui nommee iez Maria (v. 89). El segundo se apoya en el «Gratia plena» para reiterar las cualidades únicas de esa extraordinaria mujer. El tercero parte de «Dominus tecum» para aludir a la concepción virginal del hijo de Dios. El cuarto está inspirado por «Benedicta tu in mulieribus» e insiste en la elección de María para su función especial y el último se cierra sobre el «Benedictus fructus ventris tui». Cada uno de ellos reserva al final unas cuantas estrofas para la solicitud de auxilio y protección para el autor, que se presenta como el más ferviente devoto, confiado en obtener las gracias que demanda ${ }^{25}$.

En total, los salus ocupan, grosso modo, 890 versos que reiteran incesantemente las mismas ideas, como si se tratase de su tan elogiado recurso a la annominatio (Kunstmann 2006, Clark 2006), pero, en este caso, trasladada al ámbito semántico. Se tiene la sensación de asistir a una monótona secuencia de paralelismo conceptual que se prolonga a lo largo de cientos de versos. En ellos se enfatiza la oposición Ave / Eva y se insiste en la condición de madre de Dios, en su dulzura y su bondad, aunque no sería justo ocultar que muchas de las estrofas contienen grandes imágenes que sobresalen por encima del monótono discurrir de centenares de versos («Tes fius le pellican en la crois resambla», v. 373, por ejemplo) o incluyen esenciales preceptos teológicos que no debieran pasar inadvertidos («Mais Dieus t' eut pourveüe ainz que

\footnotetext{
${ }^{24}$ El Prólogo de los salus es bien claro: «A la fin de cest libre, ou j' ai pené jor maint, / salüer weil la dame ou toute douceur maint» (II Sal 35, vv. 1-2).

${ }^{25}$ Me pregunto si esta curiosa forma de realzar el Avemaría no tendrá algo que ver con la aparición de esta nueva plegaria, que, desde 1198, acompañó al Credo en los rezos tradicionales por consejo sinodal: «Que les prêtres exhortent sans cesse les fideles à dire l'oraison dominicale, le Credo in Deum et la salutation de la Vierge» (citado en Bériou, 1991: 172). Los tiempos, los emisores del mensaje y los propósitos coinciden.
} 
fust Adan nez», v. 482), entre la reiteración de aquellos más conocidos («Ave virge en cui char la chars Dieu fu membree», v. 491). En realidad, estos extensos «saludos» podrían condensarse en esta estrofa del cuarto (II Sal 35, vv. 457-460):

Ave dame des angeles. Cuers penser ne set mie

Com de Dieu iez amee. Sa mere iés et s'amie,

Sa mere iés et sa fille ; tex fiex est et tes père.

Qui ne le croit ensi laidement le compere.

Antes de este largo epílogo y una vez rematado su libro segundo, Gautier había admitido que ya ha contado buena parte de los milagros de la Virgen («A mon pooir vous ai retrait / de ses myracles grant partie», II Epi 33, vv. 9-10), y que, aunque podría contar más, pues son tan hermosos que podría escribir un tercer libro («Encor feisse le tiers libre», v. 62), ya se encuentra cansado («toz sui las», v. 13) y mentalmente fatigado («... se tres dure / la teste eüsse et bien delivree», vv. 60-61), de modo que ha decidido poner punto final a su obra. Sin embargo, como hemos visto, quedaban todavía muchos versos por escribir, aunque hubiese dado ya la obra por finalizada: «Cest libre, ou a mise s'entente, / a toz cialz envoie et presente, / qui en cuer ont et em mimoyre / la douce mere au roy de gloyre». (II Dout 34, vv. 4-6) ${ }^{26}$.

Por su parte, recordemos que Alfonso X había cerrado su primera colección de cien poemas con la CSM $100^{27}$ que era una larga oración de súplica a la Virgen para que, en el día del juicio final, cuando todos nos encontremos ante el implacable juez, ella actúe como abogada nuestra («fas com' avogada, ten voz de nós, pecadores», CSM 422, v. 59) y le recuerde a su hijo todos los momentos de tribulación y congoja sufridos durante su vida en la tierra por causa suya y, de ese modo, consiga ablandar su ira para que sea benévolo con nosotros en su sentencia. A continuación, pasa de esa petición general a la petición particular y se dirige personalmente a la Virgen suplicándole «que rogues a teu fillo Deus que el me perdón / os pecados que fige, pero que muitos son» (CSM 10128), y es en esta cantiga donde por primera vez la obsequia con el libro «dos miragres teus» (v. 12) que acaba de componer y le solicita,

${ }^{26} \mathrm{~A}$ esta larga composición moral que sucede al Epílogo de su Libro II, todavía debe añadirse la serie de los Salus con su prólogo, tal como se ha señalado, lo que hace un total de 3.641 versos.

${ }^{27}$ CSM 100 en To, Festa 12 en E, CSM 422 en Mettmann. No se pierda de vista que la colección primigenia de poco más de cien cantigas fue reestructurada, cuadriplicando el número de textos que fueron copiados en dos contenedores de gran complejidad formal por cuanto exhibían un texto iconográfico al lado del versificado. Vid. Parkinson 2011.

${ }^{28}$ Cantiga de Petiçón, que ocuparía el lugar 101 en To, pero el 401 en E, numeración que coincide con la de Mettmann, como se sabe. 
en compensación por el servicio rendido, el galardón que le había requerido cien composiciones atrás, en el prólogo ${ }^{29}$.

Con esta personal cantiga de cierre, de diez estrofas de diez versos, parecía haberse dado por finalizada la colección de cien composiciones, tal como se había concebido inicialmente, y estas dos últimas cantigas mencionadas parecen, efectivamente, una clausura perfecta para una obra que quedaba especularmente cerrada: «Pois cen cantares feitos acabei e con son, / Virgen, dos teus miragres, péçoch'ora por don.... ${ }^{30}$. Sin embargo, en el fol. 136r, a continuación de los últimos versos de la pitiçon, una rúbrica en prosa anuncia la continuación al proyecto: «Pois que el rey fez cen cantares de milagres e de loor de Santa Maria e ouve feita sa pitiçon, teve por ben de fazer outras cinco cantigas das festas do ano»y, seguidamente, nos encontramos la rúbrica de la primera cantiga «das festas», que canta el nacimiento de la Virgen.

Si volvemos la mirada a los textos de Gautier, observaremos que también el primer salut, aquel en el que se deletreaba en nombre de MARIA, contenía una segunda parte que aludía al nacimiento de la Virgen («Buer fusses engenree de Joachim et d' Anne», v. 144), lo cual coincide con lo que se desarrolla por extenso en la cantiga alfonsí. Las primeras estrofas de esta Primeira Festa hacen referencia a la profecía del Antiguo Testamento (Is 7, 14), según la cual una doncella encinta daría a luz a un varón, al que pondría de nombre Emmanuel, así como a su selecta estirpe (Is 11,1 ), versos que casi coinciden con aquellos otros contenidos en el segundo salut de Gautier, como se podrá comprobar:

E daquesta naçença falou muit' Ysaía, e prophetando disse que arvor sayria ben de rayz de Jesse, e que tal fror faria que do Sant' Espirito de Deus fosse morada. Bẽeyto foi o dia e benaventurada...

Outros prophetas muitos daquesto profetaron, e os Evangelistas desta Sennor falaron com' era de gran guisa, e dos Reys ar contaron do linag' onde viynna esta Sennor onrrada. Bẽeyto foi o dia e benaventurada... (Primeira Festa en To $=$ CSM 411, vv. 5-14)
Ave vierge. Ysaïes de toy prophetiza. Daniel, Geremies chascuns t'autoriza. Tuit parlerent de toy et de ta nacion Mil anz et plus assez ainz l' incarnatïon.

Ave seur toutes fames a bien faire alignie.

Estraite fus et nee de la David lignie.

Tuit li prophete distrent plus de mil anz devant Que li fiuz Dieu seroit nouris en ton devant (II Sal 35, vv. 225-232)

\footnotetext{
${ }^{29}$ Recordemos: Onde lle rogo, se ela quiser, que lle praza do que dela disser / en meus cantares e, se ll' aprouguer, / que me dé gualardon com'ela dá / aos que ama; e queno souber, / por ela mais de grado trobará, (vv. 39-44).

${ }^{30}$ Como se recordará, este verso tuvo que ser modificado cuando esta cantiga se convirtió en el cierre de cuatrocientas cantigas, en el Códice E.
} 
Aún más reveladora me parece la Segunda Festa de la Virgen en To (CSM 415), que celebra la Anunciación por parte del ángel. Bajo la marca de la brevitas que caracteriza todas las cantigas del Sabio, se condensa en una delicada cantiga de solo treinta y dos versos aquella larguísima serie que constituyen los cuatro salus que el Prior había confeccionado en torno a las palabras de Gabriel en su encuentro con María (vid. supra). La primera estrofa del texto alfonsí es una amplificatio de los versos del refrán refrán con que se abre la cantiga (Tan bẽeyta foi a saudaçon / per que nos vẽemos a salvaçon) $\mathrm{y}$, cada una de las estrofas sucesivas, compuestas en torno al conocido saludo, desarrollan algunas nociones clave del dogma de la encarnación de Jesús: «Ave» enlaza con la idea de la encarnación del hijo de Dios en el vientre de María; "Graçia plena» con los beneficios de la corporeidad de Dios para los hombres; «Contigo é Deus» anuncia su pasión y muerte para cumplir con su misión salvífica; «Bẽeita es tu / entr’ as molleres» recuerda el nacimiento de Cristo y la visita de los Magos y, por último, «Beeyto será / aquel fruito que de ti nacerá» alude a la redención de los pecados de la humanidad. Aunque los tradicionales términos de la salutación no eran desconocidos para ninguno de los miembros del equipo que trabajase en la composición de las CSM, me parece factible que hubiese encontrado en la obra de Gautier la inspiración de componer una canción en torno a las palabras textuales del ángel, aunque Alfonso supo adaptarla sabiamente de acuerdo a sus propósitos: transcribe las palabras en romance y condensa todo el saludo en una ligera cantiga que no descuida la transmisión del mensaje esencial, o sea, la imprescindible encarnación del hijo de Dios en el vientre de María para poder llevar a cabo su misión redentora.

Pareciera, pues, que, examinando la colección de Gautier, surgiese la idea de componer y añadir esta secuencia de las Festas, pero Alfonso prefirió explotarla al máximo y extrajo el contenido de los salus y lo reorganizó, precisamente, bajo una secuenciación ordenada en torno a las fiestas de la Virgen conmemoradas por la Iglesia. Se ha señalado ya qué se incluye en la Primeira y Segunda Festa y sus concomitancias con los textos del francés. En la Tercera Festa (CSM 413), dedicada a la virginidad de María, nos encontramos con la metáfora, difundida por Bernardo de Claraval, del cristal que atraviesa la luz sin romperlo (vv. 25-33), lo mismo que en los vv. 237-240 del salut. Sin embargo, no encuentro ni la cuarta fiesta, que conmemora la presentación en el templo ni la quinta, sobre la asunción de la Virgen, en los salus franceses, más centrados en la encarnación de Cristo y en su posterior pasión y muerte, momentos de tanto sufrimiento para su madre y que aparecen varias veces 
recordados a lo largo de la extensa composición del benedictino ${ }^{31}$. Me parece plausible que, habiendo empezado una secuencia individualizada para cada una de las Festas, el Sabio no quisiera dejarla inacabada; que no estuviesen entre los versos franceses no quiere decir más que en el Scriptorium se aprovechó aquella idea que estaba embrionaria y que supieron desarrollarla con evidente éxito. Y lo mismo pudo ocurrir con los versos que contienen los pasajes de temática cristológica: el Sabio prefirió darle amplitud y dedica cinco cantigas a conmemorar las cinco fiestas de Cristo que agregó, especularmente, a continuación de las fiestas de su madre.

Por el contrario, nada de esto podemos encontrar en la colección del monje riojano, pues sus Milagros se cierran con ese enigmático relato de «La iglesia robada $»^{32} \mathrm{y}$, aparte de la original introducción al libro, llena de metáforas y alegorías (recursos, estos sí, fácilmente identificables en la tradición), no contiene más que la relación de milagros que la Virgen opera en favor de diferentes devotos, hombres (religiosos y laicos casi en la misma proporción) y mujeres (dos: una laica, milagro 19, y una monja, el 21) ${ }^{33}$. Como suele ser habitual en las colecciones latinas tradicionales, no hay ni una sola oración a la Virgen y, desde luego, ni una sola canción, género que realmente hubiese marcado un hito muy significativo por encuadrarse en el mester de clerecía. Al contrario, sus veinticinco milagros transcurren uno a continuación de otro, en una sucesión ininterrumpida de perfectos tetrástrofos monorrimos ${ }^{34}$, encadenados a partir de la Introducción que actúa a modo de prólogo de la colección, y desde cuyos versos finales advierte que va a dar comienzo el relato de los milagros de la Virgen, implorando, desde la humilitas, su auxilio para la ejecución de tan costosa obra, pues, como dice al principio del primer

\footnotetext{
${ }^{31}$ Noción que se repite insistentemente: vv. 232, 272, 313-320, 473, 485-488, 491, 493, 501, 525-540, 557-576.

${ }^{32}$ En aquellos manuscritos que así transmiten la obra, pues otros hay que cierran con el milagro de Teófilo, de larga tradición, contrariamente al de la iglesia robada, que podría ser original de Berceo, pues no se han encontrado otras versiones anteriores que lo contengan. Puede verse el resumen de la interesante discusión acerca de qué milagro debe poner el broche final a la colección del riojano en Baños 1997: LXIILXXII, donde se indica también la bibliografía precedente que trata esta cuestión.

${ }^{33}$ La prevalencia de protagonistas masculinos podría estar en relación con el público a quien iba destinada la obra, que serían los novicios a los que Berceo tendría que adoctrinar, de compartir la tesis de Uría (1997: xIX).

${ }^{34}$ Como se recordará, Berceo compone un larguísimo poema de novecientos once tetrástrofos monorrimos que los editores dividen en Introducción y una serie de veinticinco milagros. No suele haber prólogos en cada uno de ellos, más allá de ciertas fórmulas proemiales que recuerdan los comienzos de los cantares de la épica («Señores e amigos, por Dios e caridat, / oíd otro miraculo fermoso por verdat» (vv. 182-183); «Aún otro miráculo vos querría contar» (v. 867), aunque es más fácil encontrar alguna estrofa, que situada al final de un determinado relato, ejerza como epílogo al mismo (como por ejemplo, vv. 74-77, 235-238, 316-319, etc.).
} 
relato, los milagros de la Virgen son tantos «ca non sé de cuál cabo empieze a contar, / ca más son que arenas en riba de la mar» (vv. 49-50).

Este modelo de cuentas enhebradas unas a otras usado por Gonzalo de Berceo recuerda un poco a otra colección de milagros de la Virgen, escrita en francés también hacia mediados del siglo XIII y que conocemos como Vie des Peres (Lecoy 1987-1999). Esta colección, ya a juzgar por el desconcertante título, presenta numerosos puntos de interés ${ }^{35}$. El primero es su propia conformación, pues, como las demás obras de las que hemos estado hablando, se trata de una compilación que muestra signos de una confección en tiempos diferentes; en este caso, se habla incluso de autores diferentes: al primero correspondería la redacción de los cuarenta y dos primeros relatos y a un segundo autor se deberían los bloques de relatos 43-50, del 64-74 y del 51-63. La Vie des Peres, en su conjunto, es un larguísimo poema de 30.251 versos octosílabos, que comienzan por una oración dirigida a Dios en la que el autor pide la fuerza y la inteligencia necesarias para acometer la obra que pretende llevar a cabo: «En voir vueil mettre mon savoir [...] Des peres ancïens vos cont» (vv. 46 y 51), es decir, se propone contar noticias relativas a personajes cuyas azarosas vidas recuerdan las de los Padres del desierto; de hecho, algunas de las primeras narraciones, entre las que se incluye el famoso cuento del niño judío que su padre arroja al horno de cocer el vidrio, se sitúan en Egipto («En Egypte jadis avit / un juif qui voirres fesoit» (vv. 429-430), con la intención de vincular más estrechamente estos ejemplos con las vicisitudes sufridas por los eremitas de la Tebaida ${ }^{36}$. Para poder llevar a cabo esta tarea, se dirige a Dios solicitando la sabiduría necesaria (vv. 23-30), puesto que el autor desea contar «sanz mensonges et sanz mesdit» (v. 29), las duras condiciones de vida que soportaron sus protagonistas por allegarse a Dios. Así, los relatos de la «Première Vie» presentan ejemplos de personajes que viven en condiciones extremas y de grandes pecadores/as redimidos/as gracias al

\footnotetext{
${ }^{35}$ Uno de ellos, tal vez el que más ha llamado la atención de los estudiosos, pero en el que no vamos a detenernos aquí, es el de su transmisión manuscrita, pues la mayoría de los códices solo contienen los cuarenta y dos relatos iniciales, en varias ocasiones, seguidos de una especie de conclusión del autor con la que parece ponerse fin a la obra. Pero hay otros testimonios (unos quince) que prolongan la obra con los relatos 43-50 y 64-74 y otros (siete) que todavía añaden los relatos 51-63, ya más tardíos (el orden en que son transmitidos los relatos de estos bloques no siempre coincide). Por comodidad, los editores hablan de la «Première Vie», «Deuxième Vie» $\mathrm{y}$ «Troisième Vie» para referirse a la primera redacción y las otras dos continuaciones. Véase el resumen de la cuestión que hace el editor (Lecoy 1987: IX-XXIII). Por su parte, Pinto-Mathieu (2009) indica las fechas de 1230-1252 para la redacción de la obra completa, aunque parece que hay que adelantar el inicio todavía una década. La «segunda parte» ha podido redactarse entre 1241 y antes de 1250 y la «tercera», entre esta fecha y 1252.

${ }^{36}$ Los ejemplos son numerosos: «En Egypte fu jardiniers», v. 3147; «Un autre conte vos devis / d'un roi ki ja fu en Egypte», vv. 3392-3393; «Il ot en Egypte jadis», v. 4347, etc.
} 
arrepentimiento, la confesión y la penitencia, cuyo valor salvífico es constantemente subrayado ${ }^{37}$ :

A Dameedeu, le roi estable,

Se rendoit confesse et colpable

Par si ke, s' ele en enchapoit,

Que la penitence feroit. (vv. 5.616).

Las narraciones, verdaderos exempla, vitae sanctorum o relatos de visiones, se presentan frecuentemente como sermones que, encadenados unos a otros, deben ser desplegados ante el auditorio a través de una introducción que dirija el sentido de la enseñanza y posteriormente explicados para resaltar el valor de la lección que debe aprenderse, poniendo el foco sobre la enseñanza moral ejemplificada, lo cual encuadra la estricta narración de los milagros entre un prólogo y un epílogo aclaratorio, modelo que recuerda el seguido por Gautier en sus Miracles ${ }^{38}$ :

Tuit devez estre sermoné;

A ce ai mon afaire atorné,

$\mathrm{Qu}$ econter vos vuel et retraire

Un biau miracle... (V.P., vv. 421-424)

Par cest conte devez savoir,

Vos ki merci volez avoir... (V.P., vv. 1153-1154)

No obstante, aunque esta estructura remita, como digo, a los $M N D$, no pretendo decir que una obra haya influido en la otra, pues probablemente ambas respondan al tradicional modelo del género. Donde sí parece que se advierte una clara influencia de los $M N D$ sobre las Vies -y que demostraría la gran difusión y prestigio que había alcanzado para entonces la colección del Prior de Vic-sur-Aisne- es en el cambio de rumbo que ha tomado el autor de la segunda y tercera partes de las Vies, puesto que los milagros oficiados

\footnotetext{
${ }^{37}$ «Ensi confession s'estent / et per .iii. choses se descoevre: / per langue, per cuer et per oeuve; / et cil qui nel set, si l'apreigne / qu'en lui confesser ne mespreigne », vv. 1098-1102). En este sentido, este y otros textos parecen hacerse eco de las nuevas ordenanzas emanadas del IV Concilio Lateranense que, en su canon 21, había emitido una disposición que exigía que todos los fieles se confesasen al menos una vez al año y en confesión privada. Por cierto, este mismo mensaje se advierte constantemente en los Milagros de Berceo (Ardemagni 1990: 135-137).

${ }^{38}$ Como se recordará, si bien Gautier iniciaba la narración de los hechos milagrosos directamente, a través de un verso del tipo «Conter vos veil [...] un myracle», una vez finalizado el relato, añadía una larga reflexión sobre los hechos que acababa de exponer y que ayudaba a conectar la anécdota con su valor propedéutico.
} 
por la Virgen desplazan a los relatos de aquellas otras experiencias vitales extremas, en los que la Madre de Dios no ocupaba un lugar relevante, por lo menos, no al inicio de la colección. Al mismo tiempo, desaparecen los epílogos propedéuticos, remplazados por una brevísima recapitulación o una invitación a alabar a Dios a su madre (sobre todo en la tercera parte), y las introducciones, que quedan reducidas a unas cuantas fórmulas exordiales, propias del género:

\author{
Un novel conte avon apris \\ Que nous avon a fere enpris \\ Et en romanz metre par rime \\ Ou consonant ou leonime. (V.P., vv. 29.140-29.143).
}

La narración se llena de color retórico, el autor se detiene en largas descripciones (que en la primera parte parecían innecesarias ${ }^{39}$ ) en las que despuntan los juegos de palabras, inspirados tal vez en los floridos versos de Gautier, y se observa una complejidad rítmica y rimática mucho mayor, que pudiese ser debida también a la influencia del prior. Encontramos ahora muchos de los milagros comunes a su repertorio y a otros anteriores y se abandonan las largas meditaciones sobre la necesidad de la salvación y las amonestaciones sobre los peligros que acechan al hombre ${ }^{40}$. La proximidad entre ambos repertorios franceses es tal que, aparte de reproducir algunos milagros comunes (lo que no sería excepcional), algunos manuscritos transmiten parte de una y de otra colección ${ }^{41}$.

Esta breve muestra de la notable influencia que ejercieron los $M N D$ en otros repertorios contemporáneos, tal como apuntaba Donà (1997: 285: «grazie al suo inmenso sucesso [...] è rimasta per tutto il Medioevo l'indiscusso modello del genere miracolistico»), me sirve para apuntalar un poco más la

\footnotetext{
${ }^{39}$ En efecto, una de las cualidades que más llama la atención de estos relatos de la Première Vie es la sobriedad, el estilo llano, casi coloquial, de su redacción que recuerda, en cierto modo, el rápido discurrir de la acción en los milagros de Berceo. La narración tiene valor por sí misma, por la intensidad de lo experimentado por los personajes, por los momentos de dramatismo vividos, por los bruscos cambios en el hilo argumental, donde el milagro no parece ser la manifestación de lo sobrenatural, sino que Dios o su madre se comportan como un personaje más, participando de la cotidianeidad de este mundo. Con todo, el autor de los relatos nunca olvida subrayar que, frente al mal y al pecado se contrapone un Cielo bondadoso y lleno de Gracia, que es el que triunfa. Por otra parte, en esta Primera Vida queda claro cuál es la intención del autor al escribir el relato: defensa de la castidad, defensa de la confesión, alerta contra los distintos tipos de pecado que amenazan la salvación del alma, como en Berceo.

${ }^{40} \mathrm{Sin}$ embargo, los $M N D$ no aligeraron el componente dogmático y mantienen hasta el final las largas colas moralizantes con las que, a partir del milagro expuesto, se sermoneaba al auditorio sobre los vicios o virtudes que se resaltaban en dicha narración.

${ }^{41}$ Véase una detallada comparación entre el tono de una y otra colección en Zink 2003: 203-250.
} 
hipótesis de la directa influencia ejercida por los $M N D$ no solo en la confección sino, y sobre todo, en la disposición del marial alfonsí y para ello considero que fue necesario tener sotto gli occhi un ejemplar de los Miracles. Solo así se pueden justificar los casos de adaptación de los textos que indicaba Marullo aunque, en muchas ocasiones se trate más bien de los casos de «intertextualidad», como advertía Parkinson (2011: 90-92), aun dudando de la posibilidad de la consulta directa ${ }^{42}$.

El otro rasgo que, con el de la disposición formal, más pudo haber llamado la atención del Rey Trovador fue la contraposición que Gautier establece entre poesía profana (que parece conocer tan bien como Alfonso) y poesía religiosa, otorgándole a esta una prevalencia indiscutible al considerar el amor divino cualitativamente muy superior al amor mundano. Cierto es que esta postura podría formar parte de la censura que el clérigo hace de la sociedad en la que vive, pues en algunos de sus milagros aprovecha la ocasión para criticar duramente los vicios que se han apoderado de la sociedad ${ }^{43}$, pero los milagros en los que se oponen amor divino y amor profano son bastantes y muchos más los versos en los que alude directamente a su preferencia.

Si en el primer prólogo, después de indicar que se dispone a traducir esos milagros del latín, advierte que no hay mayor y mejor servicio que el comprometido con la Virgen («Tuit li saige doivent savoir / qui bien la sert qu' il fait savoir», vv. 11-12 y en 118-126 y 265-268), para continuar después ensalzando las virtudes de la madre de Dios, en el segundo se centra más

${ }^{42}$ En mi opinión, es cierto que, en ocasiones, Marullo parece haberse dejado llevar por la emoción de haber creído encontrar una fuente románica directa al señalar los milagros de Gautier como tales. Es verdad que en numerosas ocasiones parece haber acertado, por ejemplo, en MND I 19 y CSM 75; MND I, 21 y CSM 42; MND I, 22 y CSM 115 entre otros. Tal vez también en los MND I, 18 y CSM 17, ya que, si prescindimos del inicio del relato y nos centramos en el núcleo, los textos muestran bastantes coincidencias; o, al contrario, los MND I, 20 y CSM 7 son similares si prescindimos de la parte final; podríamos dar por semejantes las narraciones MND I, 13 y 14 y las CSM 34 y 32, respectivamente, pero, por ejemplo, no me parece que la CSM 47 sea la adaptación de MND I, 16 y otro tanto se podría decir de la CSM 404 y el MND I, 17, por señalar solo algún caso notable.

${ }^{43}$ En este sentido es muy clarificador el milagro I, 19 (retomado por Alfonso en la CSM 75) en la que se contraponen las vidas de un rico usurero y una mujer muy pobre. El relato gira en torno al momento de la muerte de ambos, uno en su rica casa, rodeado de demonios, la otra en una pequeña cabaña, acompañada por la Virgen y los ángeles. Además de la fácil comparación que puede establecerse por el destino que da a las almas de uno y otra de acuerdo al tipo de conducta observada a lo largo de sus vidas, Gautier no escatima versos para criticar directamente el excesivo apego a los bienes materiales por parte de ciertas clases sociales, y sentencia que «Tuit de male mort morront» (v. 571). Pero la crítica puede aparecer en cualquier lugar; así, acabado el milagro de Teófilo, en el sermón consecutivo se hace un furibundo repaso a los vicios y pecados que dominan el estamento eclesiástico, desde el olvido de la caridad a la práctica de la homosexualidad. Alfonso, por el contrario, se limita a exponer los hechos desnudos y a dejar que el auditorio saque sus propias conclusiones. 
directamente en el provecho o perjuicio del ejercicio poético, dependiendo de la materia tratada:

Qui que vos chant chançons polies

De risees et de folies,

Je ne veil pas chanter tex chans,

Car trop i a pleurs et deschans :

L'ame sovent pleure et deschante

Dou chanteür qui tex chans chante. (I Pr 2, vv. 63-68)

¿No parece que, al escuchar esta amonestación, Alfonso decidiese ponerse de parte del francés y hacerse él también trovador de la Virgen y renegar de los amores mundanos? Como el Prior, conoce bien la literatura profana, domina el arte de la composición poética y es un trovador abierto a la experimentación con nuevas posibilidades temáticas o formales ${ }^{44}$. La exaltación de la figura de la Virgen «madre y amiga» le abriría solo a él una puerta no franqueada hasta entonces en gallego-portugués. Alfonso recoge la invitación a alinearse en contra del amor que también denosta Gautier, quien declaraba insistentemente que no era bueno cantar ese tipo de amor, cuyas funestas consecuencias son bien conocidas ya (en alusión a la canción trovadoresca) y que quiere dedicarse por entero al nuevo canto que ensalza el amor divino. El Sabio proclamará ese mismo principio en versos que se asemejan ${ }^{45}$ :

Amors, qui seit bien enchanter, As pluisors fait tel chant chanter Dont les ames deschantent.

Je ne veil mais chanter tel chant, Mais por celi novel chant chant De cui li angle chantent (I Ch 3, vv. 4-6)
Esta dona que tenno por Sennor e de que quero seer trobador, se eu per ren poss' aver seu amor, dou ao demo os outros amores. Rosa das rosas e Fror das frores... (CSM 10, vv. 19-23)

Y, como Gautier, que había «plantado» flores con las que «tout enflorer volrai[t] cest libre» (v. 44) dedicado a «La sainte flors, la sainte rose» (v. 49), así el rey castellano compone cantigas de loor en las que proclama su amor

\footnotetext{
${ }^{44} \mathrm{Su}$ curiosidad por las formas poéticas novedosas, el gusto por los juegos del lenguaje, su participación en duelos poéticos, etc. quedan bien al descubierto en sus cantigas de escarnio. Vid., para una revisión general de su producción, Paredes 2010.

${ }^{45} \mathrm{El}$ dolor que expresa la canción profana frente a la alegría y bienestar que destila la canción de amor a lo divino es constantemente repetido en los Miracles: I Pr 2, vv. 63-73; I Ch 3, vv. 7-12, 49-54; I Ch 4, vv. 1-9; II Sal 35, vv. 261-268 y 409-416. Por su parte, Alfonso no se cansa de repetir la satisfacción obtenida después de haber tomado la decisión de abandonar amores terrenos por el celestial: CSM 140, $160,170,200,260$, que culminan en la CSM 130, verdadero alegato contra la dama de la poesía profana que redunda en la exaltación de María (Fidalgo 2001).
} 
por la «Rosa das rosas e fror das frores» $\left(\mathrm{CSM} \mathrm{10,} \mathrm{v.} \mathrm{1)}{ }^{46}\right.$, pues solo «A tal sennor dev' ome muit' amar» (v. 9), así que decide abandonar la práctica de la poesía mundana («quero ser oimáis seu trobador [de la Virgen]», Prólogo, v. 19), siguiendo aquellos consejos que el otro brindaba en numerosas composiciones:

Qui que fase rotruenge novele,

Pastorele, son, sonet ne chançon,

Je chanterai de la sainte pucele

$[\ldots]$

Je ne veil mais chanter se de li non;

D'autre dame ne d'autre damoisele

Ne ferai mais, se Dieu plaist, dit ne son.

(I Ch 4, vv. 1-9)

Gautier nunca desperdicia la ocasión de reiterar su desdén por la literatura de carácter profano ${ }^{47}$ y por las actitudes y amor caballeresco. Constantemente se refiere al amor humano como un «fol amor» que conduce a la «folie», entendida esta como un pecado ( 1 Ch 5, vv. 52-56), ya que ese amor no es más que «fol delit» (I Mir 22, v.22), una llama que se apodera de cuerpo y mente (I Mir 22, v. 35) y que, naturalmente, es cosa del diablo (I Mir 26, vv. 19-23). En este sentido, es muy clarificador el milagro 17 del primer libro, que cuenta cómo un clérigo abandona sus deberes religiosos «et tout au siecle se dona [...], seculers fu a desmesure» (vv. 8 y 9), «tant qu'il chaï en un malage» (v. 32), pues se vio tan gravemente aquejado del mal de la rabia que llegó a arrancarse la lengua y los labios a mordiscos. La explicación que ofrece Gautier para que este milagro se entienda correctamente confronta el provecho de amar a la Virgen, que siempre procura la salud (del alma, que es la que interesa), y los terribles efectos que produce el amor mundano, interpretado como una grave enfermedad ${ }^{48}$. Siguiendo este modelo propuesto,

\footnotetext{
${ }^{46}$ Por cierto, este verso es idéntico a otro de una canción de Gautier (I Ch 8, v. 6: Rose des roses, fleurs des fleurs), composición en la que se juega con el apelativo «flor» y «dame» (Dame d'aval, dame d'amont, v. 33), como en el conocido refrán alfonsí. ¿Se trata únicamente de intertextualidad?

${ }^{47}$ Como lo demuestra en el Prólogo del segundo libro, en el que dice que se dispone a componer un segundo libro porque sus milagros son «plus delitant $[\ldots]$ as bonnes gens $[\ldots]$ que de Renart ne de Romer / de ne Tardiu le limeçon» (vv. 46-49), es decir, son más provechosos para la gente que las historias que pueden encontrar en el Roman de Renart, que, probablemente, le disputaría la audiencia.

${ }^{48}$ Una descripción del amor tal como lo viven los caballeros de los romanz se encuentra en el I Mir 41, en el que se cuenta cómo un caballero, enamorado de una dama que no lo corresponde, no deja de acudir a lides y torneos en los que demostrar su amor, aunque sin éxito, y sufre los síntomas clásicos que conocemos desde Ovidio y que perpetúan los trovadores. La Virgen viene descrita como cualquier dama (como se había hecho y muy por extenso en el I Mir 31), y se autodenomina «loial amie» (v. 225). El
} 
Gautier insiste que solo el amor a ella es «fine amor» (I Mir 21, v. 55) y que únicamente con Nuestra Señora debe comprometerse el hombre, que será así salvado del infierno y conducido al Paraíso (I Ch 9, vv. 1-16).

En consecuencia, se observa una férrea defensa de la castidad, desde luego entre gentes de iglesia, pero también entre laicos. El matrimonio solo está bien considerado si prima la observancia de la castidad entre ambos cónyuges $^{49}$, solo rota para el necesario acto de procreación, como en el caso del I Mir 22 (que se corresponde con la CSM 115), cuya acción tiene por protagonistas a una pareja que, después de haber tenido a su primer hijo, «Li preudom et la preudefame», «d'un seul lit firent deus faire» y decidieron que «n'assambleroient en un lit / por deliter en fol delit» (vv. 16-22) $)^{50}$. Pero, una noche, el hombre «enflamez fu d'une tel flame» (v. 35) que yació con su mujer quien, incapaz de contener a su pecador marido, prometió al demonio el hijo que podría nacer de ese encuentro, aunque, como relata la historia, olvidó esa promesa, con las nefastas consecuencias que habría de conllevar. La enseñanza que se extrae de este milagro conecta con la introducción del mismo y se resume en los versos 465-468: «Humaine amor jete luez puer, / humaine amors ses amis fausse, / mais Nostre Dame n'est pas fausse». Por eso el benedictino no deja de subrayar que el mejor matrimonio es aquel que se contrae con la Virgen e invita constantemente a su auditorio a "casarse» con Nuestra Señora, siguiendo su propio ejemplo: I Ch 5, vv. 53-72 o I Ch 4, vv. 26-36.

Sin embargo, esta semilla no fructifica en el scriptorium alfonsí, tal vez porque en Castilla, el autor es un hombre (felizmente) casado y no un hombre de iglesia como el francés. Encontramos en las Cantigas relatos de matrimonios felices y otros que no lo son tanto; matrimonios traicionados, matrimonios castos y otros cuyos miembros son castigados por no serlo, pero no se oye aquella llamada que retumbaba en los versos de Gautier urgiendo al rechazo de experiencias vitales laicas, aunque no faltan cónyuges, protagonistas de numerosas cantigas, que, de común acuerdo, abandonan el siglo y entran en sendas órdenes religiosas: la vía del ejemplo puede funcionar tan bien como la reprensión.

mismo relato se cuenta en la CSM 16, pero, como siempre, en una versión mucho más reducida que no descuida la dialéctica entre los dos tipos de amor. Por cierto, no es casual que el monje del otro milagro se arranque dos de los órganos directamente involucrados en las manifestaciones del amor profano.

${ }^{49}$ Virtud que, fuera del matrimonio, es requerida si no se quiere acabar directamente en el infierno (II Mir 26, vv. 157-174).

${ }^{50} \mathrm{El} \mathrm{mismo} \mathrm{«fol} \mathrm{delit»} \mathrm{(v.} \mathrm{98)} \mathrm{de} \mathrm{la} \mathrm{cantiga} \mathrm{alfonsí} \mathrm{que,} \mathrm{como} \mathrm{supone} \mathrm{Marullo,} \mathrm{puede} \mathrm{estar} \mathrm{inspirada}$ en la francesa pues hay numerosos rasgos, como el anterior, que así lo indican. 
A modo de conclusión y ya para recapitular: partí de la hipótesis de que Alfonso X debió de conocer de primera mano alguna de las múltiples copias que se hicieron de los Miracles de Nostre Dame del francés Gautier de Coinci y que esta colección debió de servirle de inspiración para construir sus Cantigas de Santa María en el formato en que hoy las conocemos. Aunque no conservamos ningún indicio de la existencia de dicha copia en el scriptorium alfonsí y no podemos asegurar el momento de su obtención, creo que el volumen pudo haber llegado a la corte cuando el rey ya se había ganado la fama de trovador mariano, aunque sus poesías (probablemente, todavía no de carácter narrativo) estaban copiadas en rotuli sueltos, no reunidas en un libro, lo cual justifica que una de las cantigas de loor aparezca también copiada entre su producción profana en el Códice de la Biblioteca Nacional de Lisboa $(B)$. La práctica de la poesía religiosa pudo haber sido incentivada por la presencia de diversos trovadores occitanos que cultivaron también poesías de amor a lo divino y que visitaron la corte castellana a partir de la década de los 60. A lo largo de estos años y, conociendo la vigorosa corriente que discurría por Occidente, el Sabio mandó reunir diferentes mariales latinos y romances para dar inicio al suyo propio y es posible que así se hiciese con el de Gautier, que exhibía una ordenación novedosa, por cuanto presentaba una estructura cerrada entre un prólogo y un epílogo líricos, de invención personal, concentrados en la exaltación del amor y alabanza a la Virgen. El Sabio organizó su propia colección sin perder de vista la del francés, pero optimizó el formato: mantiene el marco personal y otorgó a las canciones de alabanza a la Virgen el número diez con una doble intención: al señalarlas con el número que simboliza la perfección identificó la superioridad cualitativa del amor que se canta en sus versos. En segundo lugar, con esta cadencia milagre/loor imita el rosario, objeto sacro utilizado para rezar a la Virgen, ya que considera el volumen reunido como una cuidada plegaria a la Reina del Cielo y, puesto que solicita un galardón a cambio, lo que él ofrece ha de ser merecedor del mismo. Concluido el marial, con un número de cien composiciones, añade las Festas de la Virgen y de Jesucristo, como Gautier había añadido los Salus al final de su libro. El paso de la primera colección a la siguiente reorganización en los Códices Ricos podría tener también que ver con el mismo modelo francés, en ejemplares bellamente ilustrados, que Alfonso X quiso convertir ya, hacia el final de su vida, enfermo y apesadumbrado, en una obra penitencial digna del perdón que necesitaba para su alma. 


\section{Referencias bibliográficas}

Alvar, Carlos (1977), La poesía trovadoresca en España y Portugal. Barcelona: Planeta/Real Academia de Buenas Letras.

Alvar, Carlos (2020), «Alfonso X, mecenas de la poesía», en Elvira Fidalgo (ed.), Alfonso el Sabio: cronista y protagonista de su tiempo. Logroño: Cilengua, pp. 137-161.

Anton, Karl-Heinz (1988), Los «Miraculos Romançados» de Pedro Marín. Edición crítica, introducción e índices. Abadía de Silos: Studia Silensia.

Ardemagni, Enrica (1990), «La penitencia en las obras de Gonzalo de Berceo», Revista de Literatura Medieval, 2, pp. 131-140.

Baños Vallejo, Fernando (ed.) (1997), Gonzalo de Berceo. Milagros de Nuestra Señora. Barcelona: Crítica.

Bautista, Francisco (2017), «Alfonso X, Bernardo de Brihuega y la General estoria», Atalaya, 17. DOI: <https://doi.org/10.4000/atalaya.2954>.

Beltrán, Vicente (2005), La corte de Babel. Madrid: Gredos.

BÉrIou, Nicole, Jacques BerLIOZ y Jacques Longère (1991), Prier au MoyenÂge. Pratiques et expériences (ss. $\mathrm{V}-\mathrm{XV}$ ). Turnhout: Brepols.

CABré, Miriam (2017), «La Vierge dans les poésies de Cerveri di Girona», en Paul Bretel, Michel Adroher y Aymat Catafau (eds.), La Vierge dans les arts et les littératures du Moyen Âge. Paris: Honoré Champion, pp. 91-102.

Chico Picaza, M. ${ }^{a}$ Victoria (2011), «La visión de "sones" y "trobas". Composición pictórica y estilo en la miniatura del Códice Rico», en Laura Fernández Fernández y Juan Carlos Ruiz Souza (coords.), Cantigas de Santa María. El Códice Rico, Ms. T-I-1, RBME (2 vols.). Madrid: Patrimonio Nacional/Testimonio Compañía Editorial, vol. II, pp. 411-442.

Clark, Robert L. (2006), «Gautier's Wordplay as Devotional Ecstasy», en Kathy. M. Krause y Alison Stones (eds.), Gautier de Coinci. Miracles, Music and Manuscripts. Turnhout: Brepols, pp. 113-125.

DíAZ y DíAZ, Manuel (1962), «La obra de Bernardo de Brihuega, colaborador de Alfonso X», Strenae. Estudios de Filología e Historia dedicados al Prof. Manuel García Blanco, Filosofía y Letras, 16, pp. 145-161.

DonÀ, Carlo (1997), «Il racconto. 2. La tradizione religiosa», en Mario Mancini (ed.), La letteratura francese medievale. Bologna: Il Mulino, pp. 276-292.

DondaIne, Alain (1974), «Les éditions de Vitas Sanctorum de Roderic Cerrato», Studia Anselmiana, 63, pp. 5-14.

Ducrot-Grandereye, Arlette (1980), Études sur les Miracles de Notre Dame de Gautier de Coincy [1932]. Genève: Slatkine. 
Duys, Kathryn A. (2006), "Gautier de Coinci's Miracles de Nostre Dame: Manuscript List», en Kathy M. Krause y Alison Stones (eds.), Gautier de Coinci. Miracles, Music and Manuscripts. Turnhout: Brepols, pp. 345-366. FAUlHABER, Charles (1972), Latin Rhetorical Theory in Thirteenth and Fourteenth Century Castile. [California]: University California Press.

FERnÁNDEZ FernánDEZ, Laura (2005), «Historia florentina del Códice de las Cantigas de Santa María Ms. B.R. 20, de la "Biblioteca Palatina" a la "Nazionale Centrale"», Reales Sitios, 164, pp. 18-29.

FERNÁNDEZ FernáNDEZ, Laura (2011), «Este livro, com' achei, fez á onr' e á loor da virgen santa maria. El proyecto de las Cantigas de Santa María en el marco del escritorio regio. Estado de la cuestión y nuevas reflexiones», en Laura Fernández Fernández y Juan Carlos Ruiz Souza (coords.), Cantigas de Santa María. El Códice Rico, Ms. T-I-1, RBME (2 vols.). Madrid: Patrimonio Nacional/Testimonio Compañía Editorial, vol. II, pp. 43-78.

Fidalgo Francisco, Elvira (2001), «Lo que nos dice la cantiga 130», en Manuel Alonso García et al. (eds.), Literatura y cristiandad. Homenaje a Jesús Montoya Martínez. Granada: Universidad de Granada, vol. I, pp. 339-349.

Fidalgo Francisco, Elvira (2012-2013), «La gestación de las Cantigas de Santa Maria en el contexto de la escuela poética gallego-portuguesa», $\mathrm{Al}$ canate, 8, pp. 17-42.

FitA, Fidel (1885), «Cincuenta leyendas de Gil de Zamora, combinadas con las Cantigas de Alfonso el Sabio», Boletín de la Real Academia de la Historia, 7, pp. 54-141.

Koenig, Frederic (ed.) (1955, 1961, 1966, 1970), Les Miracles de Nostre Dame par Gautier de Coinci (4 vols.). Genève: Droz.

Kuntsmann, Pierre (ed.) (1982), Le Gracial. Ottawa: Publications de l'Université d'Ottawa.

Kunstmann, Pierre (2006), «L'Annominatio chez Gautier: vocabulaire et syntaxe», en Kathy. M. Krause y Alison Stones (eds.), Gautier de Coinci. Miracles, Music and Manuscripts. Turnhout: Brepols, pp. 101-112.

Lecoy, Félix (ed.) (1987-1999), La Vie des Peres. Paris: Société des Anciens Textes Français (3 vols.).

MARTINs, Mario (1963), «Bernardo de Brihuega, compilador do Livro e legenda que fala de todolos feitos e paixões dos Santos Mártires», Brotéria, 76, pp. 413-423.

Marullo, Teresa (1934), «Osservazioni sulle Cantigas di Alfonso X e sui Miracles di Gautier de Coinci», Archivum Romanicum, 18:4, pp. 495-539. Mettmann, Walter (ed.) (1986-89), Alfonso X, el Sabio. Cantigas de Santa Maria. Madrid: Castalia (3 vols.). 
Mettmann, Walter (1991), «Os Miracles de Gautier de Coinci como fonte das Cantigas de Santa María», Estudos portugueses. Homenagem a Luciana Stegagno Picchio. Lisboa: DIFEL, pp. 79-84.

MiQuel JuAn, Matilde (2017), «La capilla real de la santa cruz en la catedral de Toledo. reliquias, evocaciones, uso y decoración», Anuario de estudios medievales, 47:2, pp. 737-768.

Nascimento, Aires Augusto (ed.) (2004), Miragres medievais numa colectânea mariana alcobacense. Lisboa: Colibri.

Paredes, Juan (2010), El cancionero profano de Alfonso X el Sabio. Edición crítica, con introducción, notas y glosario. Santiago de Compostela: Universidade de Santiago de Compostela (Verba, Anexo 66).

PARKInson, Stephen y Deirdre JACKSON (2006), «Collection, Composition and Compilation in the Cantigas de Santa Maria», Portuguese Studies, 22, pp. 159-172.

Parkinson, Stephen (2011), «The Cantigas de Santa Maria as Miracle Collection», en Laura Fernández Fernández y Juan Carlos Ruiz Souza (coords.), Cantigas de Santa María. El Códice Rico, Ms. T-I-1, RBME (2 vols.). Madrid: Patrimonio Nacional/Testimonio Compañía Editorial, vol. II, pp. 83-104.

Pichel, Ricardo (2021), «Las Vidas y Pasiones de los apóstoles de Bernardo de Brihuega a la luz de un nuevo testimonio castellano», en Marina Serrano Marín, Belén Almeida y Fernando Larraz (eds.), Babel a través del espejo. Homenaje a Joaquín Rubio Tovar. Alcalá de Henares: Editorial Universidad de Alcalá, pp. 55-67.

Pinto-Mathieu, Élisabeth (2009), La «Vie des Pères». Genèse de contes religieux du XIII ${ }^{e}$ siècle. Paris: Champion.

Resende De OliveIRA, Antonio (1995), Trobadores e xograres. Contexto histórico. Vigo: Xerais.

Rossi, Germán y Santiago Disalvo (2009), «El trovador y la rosa: huellas de las chansons marianas de Gautier de Coinci en las Cantigas de Santa María de Alfonso X», Medievalia, 41, pp. 42-59.

Salvador Martínez, H. (2003), Alfonso X, el Sabio. Una biografia. Madrid: Ediciones Polifemo.

SÁnchez AmeiJeiras, Rocío (2002), «Imaxes e teoría da imaxe nas Cantigas de Santa María», en Elvira Fidalgo, As Cantigas de Santa María. Vigo: Xerais, pp. 247-330.

StOnes, Alison (2006), «Owners of Miracles de Nostre Dame Manuscripts», en Kathy M. Krause y Alison Stones (eds.), Gautier de Coinci. Miracles, Music and Manuscripts. Turnhout: Brepols, pp. 407-442. 
StONES, Alison (2010), «Les prières de Gautier de Coinci, leur distribution et leur réception d'après la tradition manuscrite», en Olivier Collet y Yasmina Foehr-Janssens (eds.), Le recueil au Moyen âge. Texte, Codex et Contexte. Turhout: Brepols, pp. 237-267.

URÍA, Isabel (1997), «Clerecía y letras vernáculas en el siglo XIII», en Fernando Baños Vallejo (ed.), Gonzalo de Berceo. Milagros de Nuestra Señora. Barcelona: Crítica, pp. IX-XXVI.

Valmar Cueto, Leopoldo (ed.) (1990), Alfonso el Sabio. Cantigas de Santa Maria [1889]. Madrid: Real Academia Española.

ZINK, Michel (2003), Poésie et conversion au Moyen Âge. Paris: PUF.

Recibido: $10 / 04 / 2021$

Aceptado: 23/06/2021 


\title{
$\cos$
}

\author{
ReFleXiones SOBRE las CANTIGAS DE SANTA MARÍA \\ Y SU RELACIÓN CON OTROS MARIALES ROMANCES
}

Resumen: Hace ya décadas que Teresa Marullo señaló los Miracles de Nostre Dame del francés Gautier Coinci como una de las fuentes directas de las Cantigas de Santa María, aunque su opinión no fue compartida por todos. En este trabajo sostengo la tesis de Marullo, pero me centro más en la disposición formal de los Miracles que en su contenido (analizado por la estudiosa italiana). Después de observar otras colecciones romances más o menos contemporáneas (Milagros de Nuestra Señora de Berceo y la anónima Vies des Peres), considero que es muy probable que en el scriptorium alfonsí se conociese físicamente algún ejemplar de los milagros del francés y que este sirvió de modelo para la confección del libro de las Cantigas. Alfonso X se fijó en la alternancia de milagros y canciones, en su presentación como un libro acabado y encerrado entre un prólogo y un epílogo de carácter lírico. En estas canciones, Gautier rechazaba firmemente la poesía de carácter profano y exaltaba el amor divino, como hará también Alfonso X.

Palabras -Clave: Cantigas de Santa María. Miracles de Nostre Dame. Milagros de Nuestra Señora. Vies des Peres. Milagros marianos romances.

\section{ReFLECTIONS ON THE CANTIGAS DE SANTA MARÍA AND THEIR RELATION TO OTHER ROMANCE COLLECTIONS OF OUR LADY'S MIRACLES}

Resumen: It has been decades since Teresa Marullo pointed out the Miracles de Nostre Dame by the Frenchman Gautier Coinci as one of the direct sources of the Cantigas de Santa Maria, although her opinion was not shared by all. In this work I support Marullo's thesis, but I focus more on the formal arrangement of the Miracles rather than on their content (analyzed by the Italian scholar). After observing other more or less coeval romance collections (Berceo's Milagros de Nuestra Señora and the anonymous Vies des Peres), I consider that it is very likely that in Alfonso's scriptorium some copy of the Miracles of the French author was physically known and that that served as a model for making the Cantigas' book. Alfonso X noticed the alternation of miracles and songs and its presentation as a finished book enclosed between a prologue and a lyrical epilogue. In these songs, Gautier firmly rejected profane poetry and exalted divine love, as Alfonso X would do.

KeYwords: Cantigas de Santa María. Miracles de Nostre Dame. Milagros de Nuestra Señora. Vies des Peres. Our Lady's miracles romance collections. 